\title{
Using a geochemical method of dissolved and insoluble fractions to characterize surface snow melting and major element elution
}

\author{
GUANGIIAN WU, ${ }^{1,2}$ PEILIN LI, ${ }^{1,3}$ XUELEI ZHANG, ${ }^{4}$ (0) CHENGLONG ZHANG ${ }^{5}$ \\ ${ }^{1}$ Key Laboratory of Tibetan Environment Changes and Land Surface Processes, Institute of Tibetan Plateau Research, \\ Chinese Academy of Sciences, Beijing 100101, China \\ ${ }^{2}$ CAS Center for Excellence in Tibetan Plateau Earth Sciences, Beijing 100101, China \\ ${ }^{3}$ University of Chinese Academy of Sciences, Beijing 100049, China \\ ${ }^{4}$ Northeast Institute of Geography and Agroecology, Chinese Academy of Sciences, Changchun 130102, China \\ ${ }^{5}$ Research Center for Eco-Environmental Sciences, Chinese Academy of Sciences, Beijing, 100085, China \\ Correspondence: Guangjian Wu <wugj@itpcas.ac.cn>
}

\begin{abstract}
A geochemical method to characterize post-depositional melting and elution is demonstrated using inductively coupled plasma mass spectrometry to measure concentrations of dissolved and insoluble fractions of major crustal elements in snow samples collected from March 2006 to January 2010 at Urumqi Glacier No. 1, Tien Shan. Dust from these samples has compositional homogeneity, suggesting that dust has a stable dissolved fraction percentage (DFP, calculated as dissolved/(dissolved + insoluble) \%). Calcium has the highest DFP (averaging $61.5 \pm 19.4 \%$ ), followed by $\mathrm{Na}(30.4 \pm 19.6 \%), \mathrm{Mg}(13.2 \pm 9.8 \%)$, and $\mathrm{K}(7.9 \pm 9.8 \%)$. Acid input can affect dissolution of $\mathrm{Na}$ and Ca. Taking DFP values of unmelted samples as the reference, the higher DFPs refer to strengthened dissolution from acid input, while the lower ones refer to elution. Based on the DFP difference between unmelted and eluted states, an elution sequence $\mathrm{Ca}>\mathrm{Na}>\mathrm{Mg}>\mathrm{K}$ is obtained. Some details such as the beginning and the ending stages of elution can be found by DFP and acid input index, while using ion concentration is not capable of this. Our results reveal that acid input is an important mechanism for DFP changes, that the DFP index can provide an effective assessment of snow elution, and that this will aid in understanding low latitude ice cores.
\end{abstract}

KEYWORDS: melt-surface, mountain glaciers, snow and ice chemistry

\section{INTRODUCTION}

The study of melting snow under current global warming is of great importance for understanding changes in the modern cryospheric environment and interpreting paleoclimate information in ice core records. Snow melting can occur quickly over several hours, while $50-80 \%$ of the pollutant load in snow can be released with the first $30 \%$ of the meltwater (Johannessen and Henriksen, 1978). This process strongly influences the ion composition of snow (Balerna and others, 2003) and causes environmental problems, such as the 'acid flush' or ionic pulse in meltwater (Tsiouris and others, 1985; Harrington and Bales, 1998). Ice cores are excellent for recording climatic and environmental change. However, for those cores drilled in areas that might undergo snow melting, the post-depositional processes, such as melting and elution, will change the firn/ice core horizons and alter the preserved information (Huang and others, 1997; Koerner, 1997). Therefore, using the impurities in snow subjected to melting as a climate indicator for the paleoclimate record will induce uncertainty.

Some researchers use the physical stratigraphy of snowpack or ice/firn cores to characterize melting. The occurrence of ice layers has been used as a direct feature to identify melting events in ice cores from Greenland and the Arctic (Alley and Anandakrishnan, 1995; Kameda and others, 1995; Fisher and others, 2012). In many cases, it is not clear from ice cores whether the snow had undergone melting and elution, especially in those that have been transformed from firn to ice. Apart from physical characteristics, is it possible to identify whether the snow/ice has undergone post-depositional melting using proxies that have been preserved in the snow deposition itself? Further, if melting did occur, how can we quantitatively characterize the degree to which melting occurred? Attempts have been made to use the concentration ratio between different ions (e.g. $\mathrm{Mg}^{2+} / \mathrm{Na}^{+}$) in snow or ice core samples as an indicator of melting and elution (Eichler and others, 2001; Watanabe and others, 2015). This method has also been used to study the ion elution effects in snowpack or ice core records in High Asia, such as at Xixiabangma (Huang and others, 1997), Tanggula (Hou and others, 1996), and Tien Shan (Li and others, 2006). The results of these studies revealed the preferential elution sequences of major ions in snowpack samples at the sites by comparing the temporal trend of concentration ratios between ions to the reference ion. However, this method might produce uncertainty since the reference ion itself is also affected by elution. And, the ion concentration ratio method is limited to the ions by ion chromatographer, while new techniques are required to provide possible more suitable result to determine the elution process. Furthermore, the dissolution of impurities (e.g. eolian dust) may change the ion content of snow, indicating that it is important to consider the post-depositional processes for a correct explanation of the glaciochemical record (Williams and others, 1992). Acid input will accelerate dissolution and change the concentration of the soluble fraction. To assess the elution sequence we therefore need to consider the effect of acid. 
The difference in the concentration profiles between the insoluble microparticles and dissolved crustal cations (e.g. $\mathrm{Ca}^{2+}$ and $\mathrm{Mg}^{2+}$ ) can also reflect post-depositional melting, although both indices were used as the dust proxy. In contrast to the soluble ions, the insoluble microparticles are the less mobile impurities in snow and will accumulate at the surface instead of percolating down with the meltwater (Kohno and Maeno, 1979). As far as we know, the insoluble fraction of dust has seldom been discussed when characterizing melting-elution processes. If the crustal dust, including the soluble (ions) and insoluble (microparticles) fraction, has the same source and a homogeneous composition, then the proportion between the two fractions, namely the dissolved fraction percentage (DFP, given as a percentage and calculated as the dissolved fraction divided by the sum of the dissolved and insoluble fraction), will be affected by post-depositional processes, and the variation in this proportion could characterize these processes and their strength.

Based on this assumption, we carried out fieldwork to collect surface snow at Urumqi Glacier No. 1 (UG1), Eastern Tien Shan and laboratory measurements of both the soluble and insoluble fractions of some major crustal elements, in order to characterize the elution by geochemical methods. This method was introduced by Zhang and others (2013), but needs further work to put into practice. In this previous study, the elution sequence through the surface snow was determined to be $\mathrm{Ca}>\mathrm{Na}>\mathrm{Mg}>\mathrm{K}$ by the change of DFP for the samples from March 2006 and December 2007. And the seasonal variation of DFP was reported. Besides the extension of the sampling period (through January 2010) and further analysis of the extended dataset, we emphasize progress in several new areas in this study:

First, we need to test that dust in those snow samples is derived from crust with natural origin and has a stable composition, which is necessary to ensure that the variation of the soluble and insoluble fraction are influenced by postdepositional elution. The stable composition also enables this technique to provide the possibility of using other elements to characterize snow melting and elution besides the major ions.

Second, the new technique of inductively coupled plasma-mass spectrometry was performed to get a more reliable result for the dissolved fractions than the ion chromatographer.

Third, the acid inputs, from anthropogenic and/or natural sources, will strengthen the dissolution of some acid-dissolvable materials, and increase the concentration of the dissolved fraction and consequently bias this proportion.

Finally, whether this proportion between the two fractions could be used to detect the post-depositional elution events needs to be tested. Furthermore, to discern the state of acid-dissolution is also important to understand the elution processes and evaluate the melting state of snow, such as the initial stages of elution and the ending of elution. The ion concentration can only provide the relative sequence of elution to a reference one, but fail to discern the state of elution.

The main purpose of this study is to elaborate on the detailed variation of soluble and insoluble fractions in these snow samples, and provide a new geochemical method to characterize snow melting and cation elution using the proportion between the dissolved and insoluble fractions.

\section{SAMPLING AND MEASUREMENT}

\subsection{Field sampling}

Surface snow samples were collected by researchers at the Tien Shan Glaciological Station weekly or biweekly at the field observation site $\left(43^{\circ} 06^{\prime} \mathrm{N}, 86^{\circ} 49^{\prime} \mathrm{E}, 4130 \mathrm{~m}\right.$ a.s.l.) in a percolation zone of the east branch of UG1, Eastern Tien Shan (Fig. 1). The mean annual air temperature and precipitation at the site are $\sim-9.1^{\circ} \mathrm{C}$ and $700 \mathrm{~mm}$ water equivalence, respectively ( $\mathrm{Li}$ and others, 2006). The glacial annual equilibrium-line altitude rose strongly since 1997 and reached to the mean of $4110 \mathrm{~m}$ a.s.l. (Ye and others, 2005). The high-level Westerlies jet stream prevails across the high mountains throughout the year.

During summer, snow was collected from the top 3-5 cm due to sufficient fresh snow. While during winter, the top 3 $\mathrm{cm}$ was sampled (Li and others, 2006). The protocols and requirements for surface snow sampling have been described in detail in previous papers ( $\mathrm{Li}$ and others, 2006; Li and others, 2007a, b; Wu and others, 2010). An acid-cleaned wide-mouth Nalgene LDPE bottle was used as the sample scoop and container. A total of 116 surface snow samples were collected from March 2006 through January 2010. Due to logistic difficulties, samples were not collected consecutively with strict time intervals, especially during the coldest period of each year (January and February). During the summer, particularly in August, strong melting could cause the bare glacier surface to be covered by brown dust (Takeuchi and Li, 2008) and no surface snow was available for sampling. The non-continuous sampling adversely affects the results. In this study, the snow samples were named using the collection date, in the format yyyy.mm.dd.

\subsection{Analytical method}

The snow samples (bottles) were kept frozen until filtration. All the samples were melted at room temperature just before filtration and filtered on LCR hydrophilic PTFE membrane filters with a diameter of $47 \mathrm{~mm}$ and pore size of $0.45 \mu \mathrm{m}$ (Millipore Corporation). The filtrations were performed in a class 1000 clean room at the State Key Laboratory of Cryospheric Sciences, Cold and Arid Regions Environment and Engineering Research Institute (Lanzhou), Chinese Academy of Sciences (CAS).

The dust on the filter was digested with super-pure $\mathrm{HNO}_{3}-$ $\mathrm{HF}$ at $150-190^{\circ} \mathrm{C}$ in polytetrafluoroethylene screw-top bombs. Quantitative elemental analyses of the digested insoluble fraction (filters) were performed using an inductively coupled plasma-mass spectrometer (ICP-MS, X-7, Thermo-Elemental Corporation, quadrupole mass) at the Institute of Tibetan Plateau Research, CAS. Detection limits (given as $3 \sigma$ of the blank filter) are tens to hundreds of parts per trillion for major elements $\left({ }^{23} \mathrm{Na},{ }^{24} \mathrm{Mg},{ }^{27} \mathrm{Al},{ }^{39} \mathrm{~K}\right.$, and $\left.{ }^{44} \mathrm{Ca}\right)$. The digestion procedure, accuracy of this method for reference materials, and laboratory blanks of the ICP-MS measurement have been described in detail previously (Wu and others, 2009, 2010).

The filtrate for each sample was collected in acid-cleaned LDPE bottles. The concentration of the major elements $\left({ }^{23} \mathrm{Na}\right.$, ${ }^{24} \mathrm{Mg},{ }^{39} \mathrm{~K}$, and ${ }^{44} \mathrm{Ca}$ ) in filtrate was measured using the same ICP-MS. The ICP-MS blank for filtrate is at least one order of magnitude lower than the lowest concentration sample for the major elements. Here we should point out that the ICPMS measurement for the dissolved filtrate was conducted 


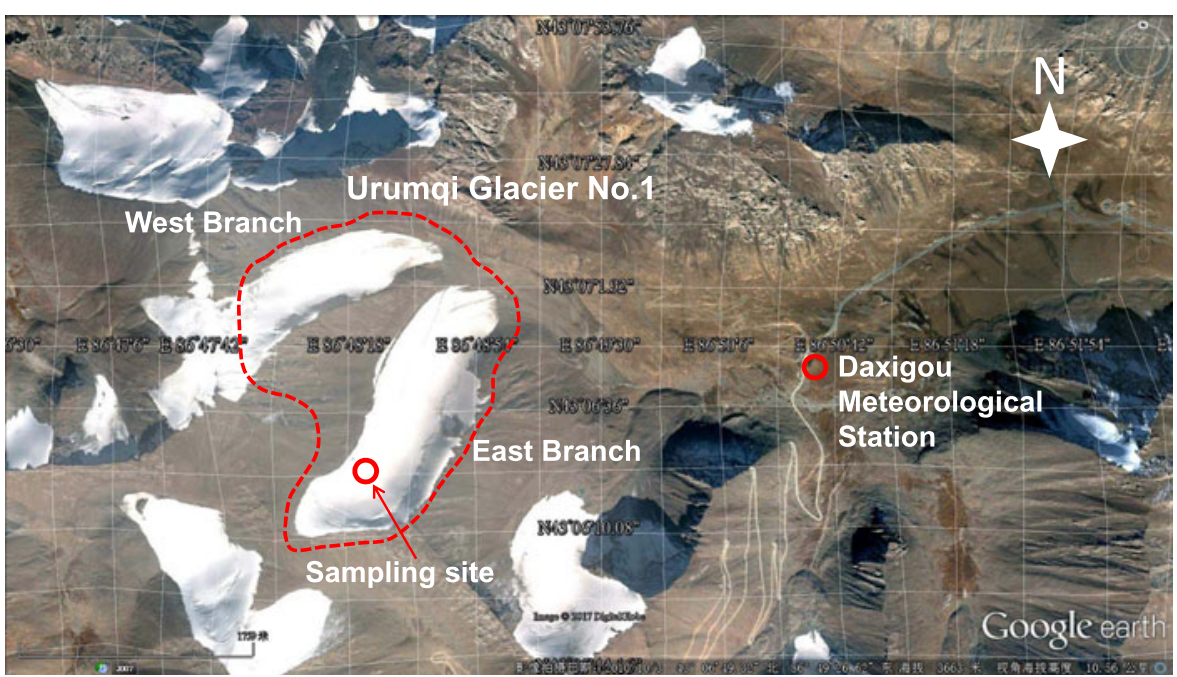

Fig. 1. Location of the sampling site on UG1, Eastern Tien Shan.

without acidification, nevertheless acidification can significantly intensify the dissolution of many species, such as iron (Wu and others, 2012). Some researchers acidify the sample and leave it for 1 week to obtain the total crustal elements. However, this pretreatment cannot dissolve the elements entirely, but will increase the concentration of the dissolved fraction (Wong and others, 2013).

The major ions $\left(\mathrm{Na}^{+}, \mathrm{K}^{+}, \mathrm{Mg}^{2+}, \mathrm{Ca}^{2+}, \mathrm{SO}_{4}^{2-}, \mathrm{NO}_{3}^{-}\right.$, and $\mathrm{Cl}^{-}$) in the filtrate were measured by an ion chromatographer (IC, Dionex 2000/2500, Dionex Corporation), with the limit of detection for all ions $<1 \mathrm{ng} \mathrm{g}^{-1}$. Liquid electrical conductivity $(\mathrm{EC})$ and $\mathrm{pH}$ were measured using a digital conductivity meter (DDB-303A, Shanghai Precision \& Scientific Instrument Co. Ltd), with precision better than $0.01 \mu \mathrm{S}$ $\mathrm{cm}^{-1}$, and a $\mathrm{pH}$ meter (PHS-3E, Shanghai INESA \& Scientific Instrument Co. Ltd), with precision better than $0.02 \mathrm{pH}$ unit, respectively. All the analyses were performed at the Institute of Tibetan Plateau Research, CAS.

\subsection{A potential geochemical index of snowmelt}

Some researchers have argued that the soluble $(<0.02 \mu \mathrm{m})$ and dissolved (soluble plus colloidal, $<0.4 \mu \mathrm{m}$ ) fractions are not the same and should be differentiated $(\mathrm{Wu}$ and others, 2001). In this study, a filter with a $0.45 \mu \mathrm{m}$ pore size was used to separate the dissolved and insoluble fractions. The filtrate was taken to be the dissolved fraction, and the residue on the filter as the insoluble fraction. The index of DFP has been used in our previous paper (Zhang and others, 2013) to quantitatively characterize the concentration of dissolved and insoluble fractions of elements in surface snow. The element content in the insoluble (dust particles on the filter, $\operatorname{ng~g}^{-1}$ snow) and dissolved fractions (filtrate, $\mathrm{ng} \mathrm{g}^{-1}$ ) of the snow samples was combined to obtain the total element content and to calculate its DFP, which is defined as DFP $=X_{\text {dis }} /\left(X_{\text {dis }}+X_{\text {insol }}\right) \times 100 \%$, where the subscripts 'dis' and 'insol' mean dissolved and insoluble. One sample was lost during digestion, therefore 115 samples remain for determining the DFP.

\section{RESULTS AND MELTING-ELUTION PROCESSES}

\subsection{The dissolved and insoluble fraction concentrations}

For the dissolved fraction of elements in snow samples, ions are often measured by IC as the dissolved fraction (Eichler and others, 2001; Li and others, 2006; Watanabe and others, 2015). This is also the same for our previous work on the UG1 snow samples (Zhang and others, 2013). Indeed, the ICP-MS and IC results for the filtrate display a very good correlation $\left(R^{2} \geq 0.98\right)$ in the dissolved concentrations of major elements, including $\mathrm{Na}, \mathrm{Mg}, \mathrm{K}$, and $\mathrm{Ca}$ (Fig. 2). However, we find that the ICP-MS has a slightly higher (all the linear fitting curve is below the 1:1 line) result than the IC, which could cause a systematic underestimation of the DFP calculation result. In this study, in order to match the same measurement technique and instrument, both the ICP-MS results for the concentration of the dissolved and insoluble fractions of these crustal elements were used to obtain the reliable DFP values. While the anion records, including $\mathrm{Cl}^{-}, \mathrm{NO}_{3}^{-}$, and $\mathrm{SO}_{4}^{2-}$, are the $\mathrm{IC}$ measurement
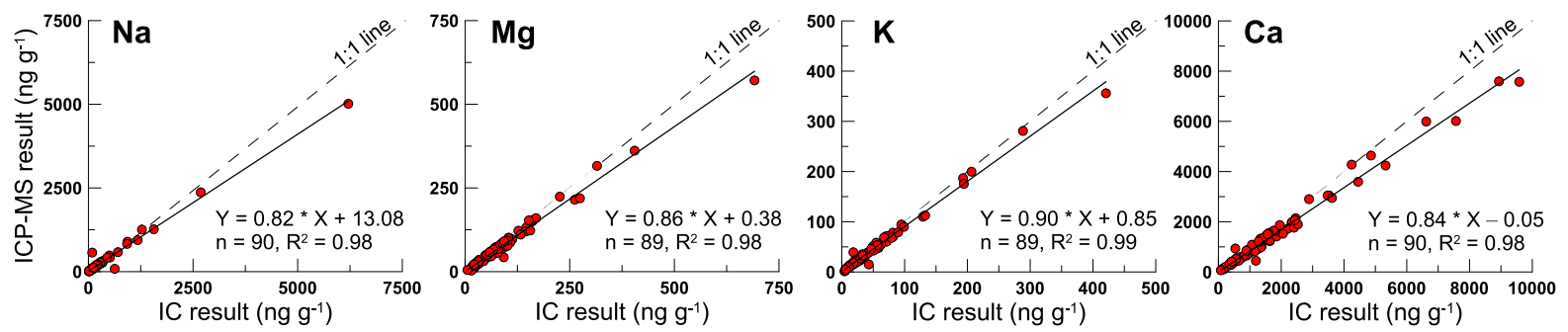

Fig. 2. The ICP-MS and IC measurement results for the dissolved fraction of major crustal elements in the UG1 surface snow samples collected from March 2006 to December 2008. 


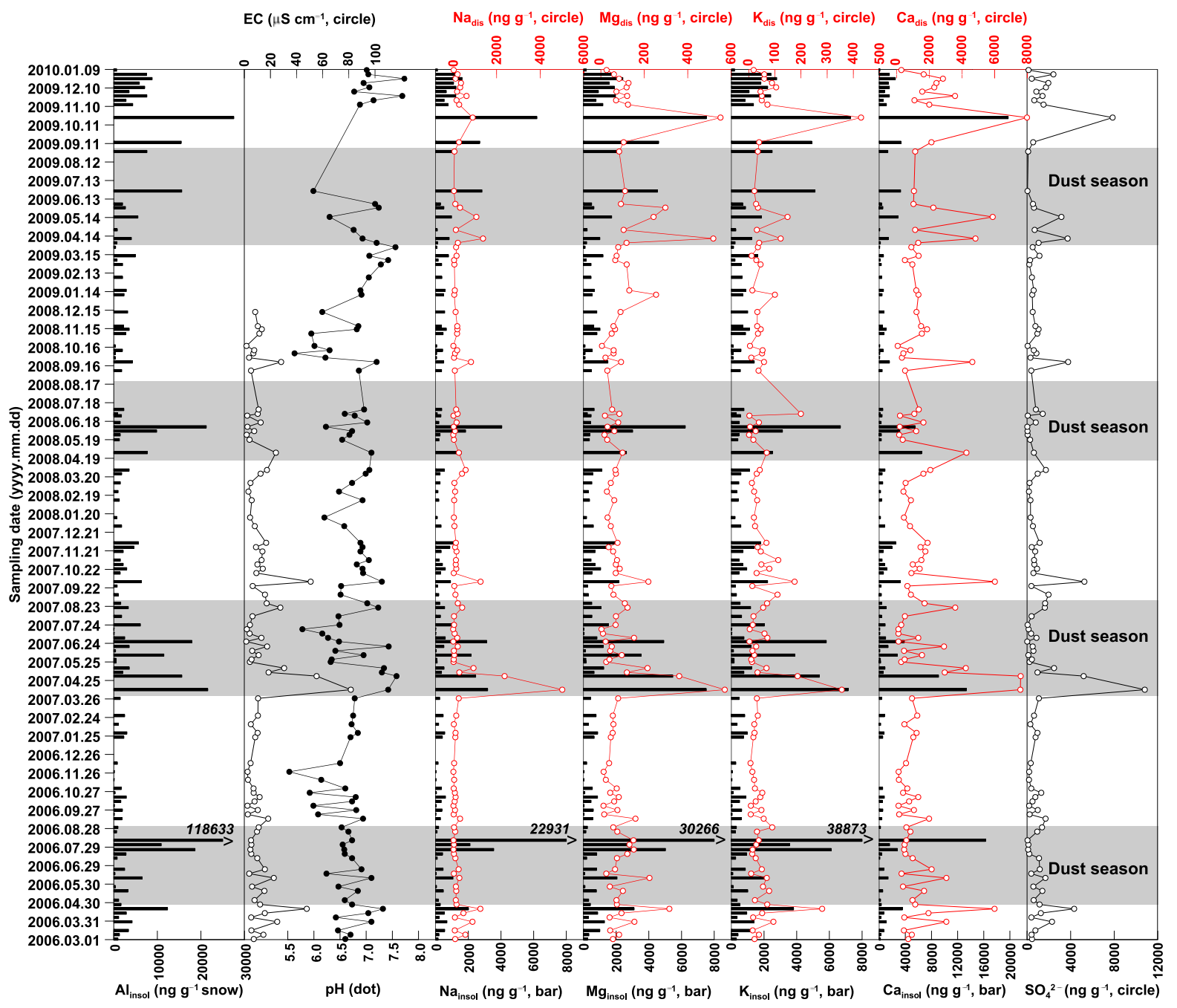

Fig. 3. Profiles of the concentration of dissolved (red circle) and insoluble (black bar) fractions of the four major crustal elements, $\mathrm{pH}$, EC, and sulfate concentration for UG1 snow samples from March 2006 to January 2010. The shaded bands indicate dust seasons (April through August). The date is presented in the format of yyyy.mm.dd.

results. The geochemical profiles of UG1 samples are plotted with time in Figure 3, and the statistics of concentration and DFP (\%) for the major crustal elements are listed in Table 1.

The concentration of the insoluble fraction of dust, as indicated by $\mathrm{Al}_{\text {insol, }}$ displays seasonal variations, with a high dust load in the dust season (April through August) and a low load in the non-dust season (September through March) (Wu and others, 2010). However, the dissolved and insoluble fraction of those major elements did not vary with the same trends or with the similar proportion in the amplitude on the scale of single samples. Some samples with high insoluble fraction have the low dissolved content, or vice versa (Fig. 3). That indicates the post-depositional processes have changed the dissolved fraction.

\subsection{The melting-elution process}

Previous studies indicate that ion elution begins when the air temperature rises above $-3.6^{\circ} \mathrm{C}$ at the UG1 sampling site ( $\mathrm{Li}$ and others, 2006). Direct air temperature and precipitation records for the UG1 sampling site are not available for our sampling period. Here we assume that temperature and precipitation at the sampling site had the same trends as the neighboring Daxigou meteorological station $\left(43^{\circ} 07^{\prime} \mathrm{N}, 86^{\circ}\right.$ $50^{\prime} \mathrm{E}, 3539 \mathrm{~m}$ a.s.l., $\sim 3 \mathrm{~km}$ east of the UG1 sampling site,
Fig. 1). The temperature data between Daxigou station and another automatic weather station at $3900 \mathrm{~m}$ a.s.l. on the UG1 glacier surface show a difference of $3^{\circ} \mathrm{C}$ during the overlapping period. Assuming a local air temperature lapse rate of $3^{\circ} \mathrm{C} / 360 \mathrm{~m}$ in this region, the temperature difference between Daxigou and the sampling site (with an elevation of $600 \mathrm{~m}$ ) is $\sim 5^{\circ} \mathrm{C}$. Therefore, elution at the UG1 sampling site was assumed to occur only when the daily air temperature was above $1.4^{\circ} \mathrm{C}$ at the Daxigou station, although melting could also occur under strong solar radiation conditions, even when the daily air temperature is lower than this threshold.

Theoretically, if the dust has the same source(s) and composition, and if there is neither acid input nor post-depositional processes, the DFP of these elements will remain consistent. Under high temperatures, when fresh snow falls onto the glacier surface, post-depositional melting and ion elution by percolation and/or flow occurs and results in decreasing ion concentration in the surface snow. Accordingly, the DFP changes based on the strength of melting and elution. If elution occurs under high temperatures, the DFP will decrease to a level lower than the unmelted case. Therefore, a low DFP clearly indicates elution. Whereas under the special condition of acid input, the DFP increases following the acid-dissolution of some 
Table 1. The statistics of concentration (ICP-MS) and DFP (\%) for the crustal elements ( $n$ means the number of samples) in UG1 snow samples, Eastern Tien Shan

\begin{tabular}{|c|c|c|c|c|c|c|c|c|}
\hline & \multirow[b]{2}{*}{$n$} & \multicolumn{2}{|c|}{ Dissolved (ng g $\left.{ }^{-1}\right)$} & \multicolumn{2}{|c|}{ Insoluble (ng g ${ }^{-1}$ ) } & \multicolumn{3}{|c|}{ DFP (\%) } \\
\hline & & Range & Mean (s.d.) & Range & Mean (s.d.) & Range & Mean (s.d.) & Median \\
\hline $\mathrm{Na}$ & 115 & $6-5013$ & $265(560)$ & $12-22931$ & 886 (2268) & $0.1-81.5$ & $30.4(19.6)$ & 25.7 \\
\hline $\mathrm{Mg}$ & 115 & $3-571$ & $96(97)$ & $28-30266$ & 1387 (3082) & $0.4-45.1$ & $13.2(9.8)$ & 10.2 \\
\hline $\mathrm{K}$ & 113 & $1-430$ & $52(63)$ & $13-38873$ & 1569 (3825) & $0.1-67.7$ & $7.9(9.5)$ & 5.2 \\
\hline $\mathrm{Ca}$ & 106 & $66-7981$ & 1533 (1606) & 83-19 731 & $1485(2926)$ & $2.9-92.6$ & $61.5(19.4)$ & 65.6 \\
\hline
\end{tabular}

materials (e.g. carbonate). The varied DFPs indicate that postdepositional processes (e.g. melting, elution, and acid-dissolution) have affected the proportion between the dissolved and insoluble fractions. The three cases, namely unmelted, eluted, and acid-dissolved, will be classified and discussed according to DFP value, acid concentration, and meteorological data in Section 4.

\section{DISCUSSION}

\subsection{The crustal source of major elements}

Using DFP to infer the degree of snow melting and elution, the source of the major elements is shown to be predominantly crustal in origin. Our previous work revealed that although seasonal variation is significant in dust concentration (insoluble fraction, more than four orders of magnitude) in UG1 snow, dust composition, as shown by elemental ratios of the insoluble fraction (e.g. L/HREE, Ce/Yb, and $\mathrm{Nd} /$ $\mathrm{Yb})$, was also rather homogeneous in samples from March 2006 to December 2008 (Wu and others, 2010). The extended samples through January 2010 also show this behavior (not shown here) and confirm this conclusion. The UG1 dust has a rather uniformity in element composition, which is independent of season and concentration. Anthropogenic pollutants, such as sulfate (Wake and others, 1992) and some trace heavy metals (e.g. Cd, Pb, and $\mathrm{Zn}$ ) (Li and others, 2007b), from the surrounding residential areas were found in the UG1 snow. The enrichment factors (using $\mathrm{Al}_{\text {insol }}$ as the reference element) of these major crustal elements $\left(\mathrm{Na}_{\text {insol }}, \mathrm{Mg}_{\text {insol }}, \mathrm{K}_{\text {insol, }}\right.$ and $\left.\mathrm{Ca}_{\text {insol }}\right)$, which are widely used to check for anthropogenic contributions, are very low $(<1.8)$ for the insoluble fraction, indicating that there are no significant distortions for these four major crustal elements. Furthermore, strong correlation was also found among those elements in soluble and insoluble fractions. The dissolved and insoluble concentrations of $\mathrm{Na}, \mathrm{K}, \mathrm{Mg}$, and Ca showed significantly positive correlation with the concentration of insoluble $\mathrm{Al}$ (a reference element of the upper continental crust) (Zhang and others, 2013), suggesting that the four elements in the dissolved fraction might have common source origins with that of $\mathrm{Al}$.

However, since the dissolved fraction is also used to calculate the DFP, whether the dissolved fraction of dust ( $\mathrm{Na}_{\text {dis, }}$ $\mathrm{K}_{\mathrm{dis}}, \mathrm{Mg}_{\mathrm{dis}}$ and $\mathrm{Ca}_{\text {dis }}$ ) has a stable composition also needs to be tested. Since the post-depositional processes that can disturb the dissolved fraction, this argumentation therefore becomes less straightforward comparing with the insoluble one. The pH (from March 2006 to December 2008) and EC (from March 2006 to January 2010) of our samples averages 6.74 and $11.93 \mu \mathrm{S} \mathrm{cm}^{-1}$, respectively; both are fairly comparable to previous findings $(\mathrm{pH}$ averaging 6.66 and $\mathrm{EC}$ averaging $12.74 \mu \mathrm{S} \mathrm{cm}^{-1}$ ) for UG1 snow samples for another period November 2002 to October 2005 (Li and others, 2007a). Here we discuss the calcium, which has the highest concentration and the maximum variation amplitude among the four cations. In UG1 snow samples for the period September 2002 to September 2004, calcium averages 1624 $\mathrm{ng} \mathrm{g}^{-1}$ (arithmetically, varying from 81 to $9586 \mathrm{ng} \mathrm{g}^{-1}$ ) ( $\mathrm{Li}$ and others, 2007a). In our ICP-MS results, dissolved calcium is the predominant cation component and averages $1457 \mathrm{ng} \mathrm{g}^{-1}$ (varying from 111 to $7593 \mathrm{ng} \mathrm{g}^{-1}$ ) from March 2006 to December 2008 and $1533 \mathrm{ng} \mathrm{g}^{-1}$ (varying from 66 to $7981 \mathrm{ng} \mathrm{g}^{-1}$ ) from March 2006 to January 2010. This is consistent with the previous study, although the sampling periods are different. Based on the agreement between the previous results and our own, the dust in UG1 snow seems to have a stable composition.

Eolian dust is a major component of the dissolved chemical content of snow packs in central Asia. Long-term observations and studies of snow geochemistry have been carried out at Eastern Tien Shan, Central Asia. High ion burdens were associated with dusty layers in the snowpack (Wake and others, 1992) or with high dust concentration in snow samples (Li and others, 2006), indicating that the vast arid regions of central Asia are the dominant source for major ions in Tien Shan snow. The dissolved fractions of major elements, which are usually measured as cations, also show crustal origin. The $\mathrm{Mg}^{2+}$ is closely correlated with dust particles and thought to be the index of dust (Li and others, 2006). The $\mathrm{Na}^{+}, \mathrm{K}^{+}$, and $\mathrm{Ca}^{2+}$ also primarily come from dust, since UG1 is remote from marine sources ( $\mathrm{Li}$ and others, 2006). Snowpack records for UG1 also indicate that the $\mathrm{Na}^{+} / \mathrm{Cl}^{-}$ ratio is slightly higher than that of seawater, suggesting that a small portion $(<12 \%)$ of $\mathrm{Na}$ might come from seawater (Williams and others, 1992).

The extended samples support our previous result (Zhang and others, 2013) that the major elements ( $\mathrm{Na}, \mathrm{K}, \mathrm{Mg}$, and $\mathrm{Ca}$ ) have the crustal source and compositional homogeneity. Therefore, this homogeneity of these major elements can provide a basis for using the proportion between the dissolved and insoluble fractions of these crustal elements as a potential index to characterize the melting-elution process and/or anthropogenic acid input.

\subsection{The effect of acid input on the DFP}

UG1 is located closely to human residential areas and receives anthropogenically emitted acidic materials, such as sulfate and nitrate (Wake and others, 1992; Williams and others, 1992). Over the sampling period, sulfate and nitrate concentrations vary greatly, with more than two orders of magnitude (Fig. 3 and 6). The sulfate concentration 

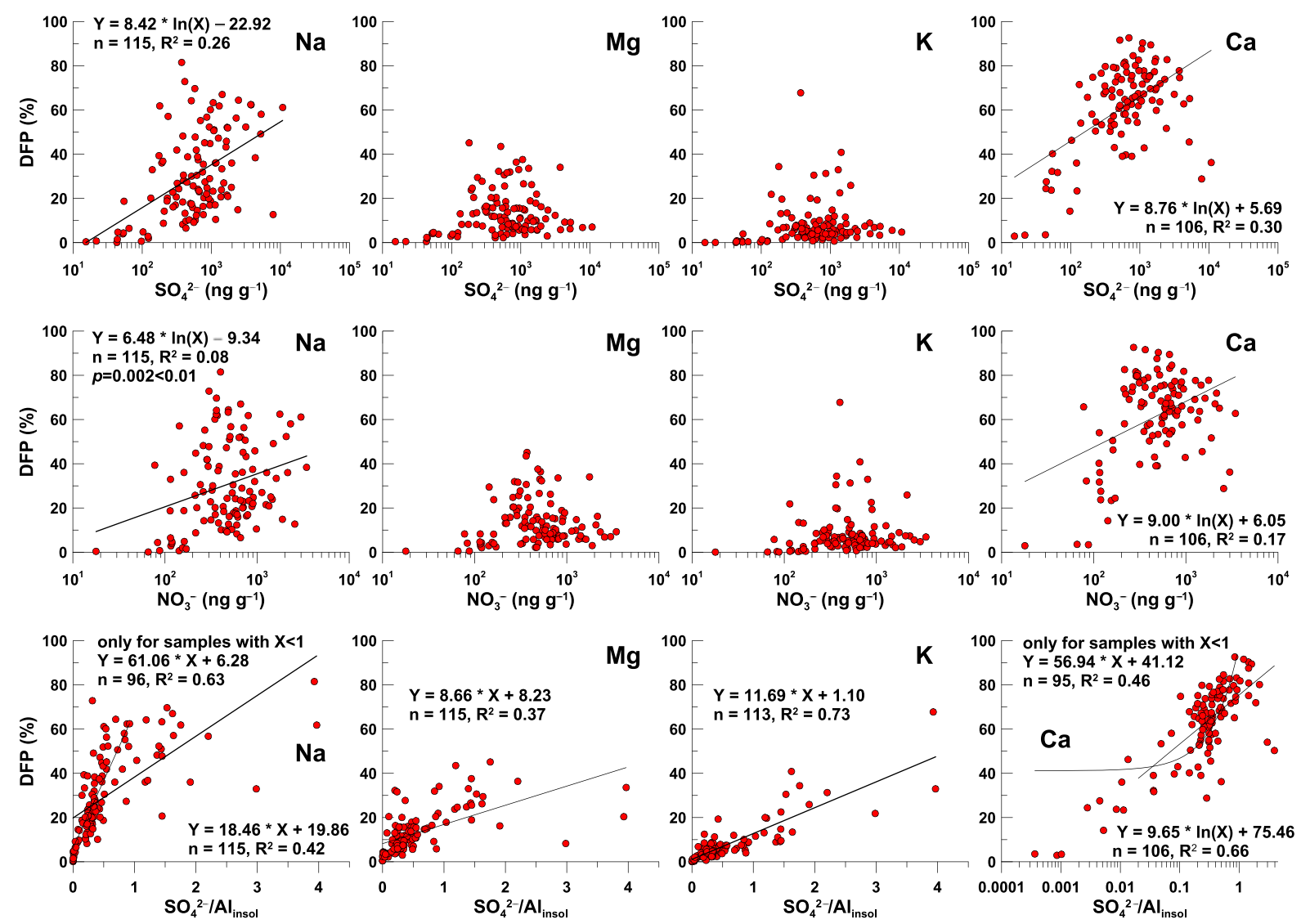

Fig. 4. The DFP of major crustal elements vs sulfate (top), nitrate (middle) concentration, and excess sulfate index $\mathrm{SO}_{4}^{2-} / \mathrm{Al}_{\text {insol }}$ (bottom) of UG1 samples. All the correlations shown in the figure are significant $(p<0.01)$. Note that the correlation between Na (and Ca) DFP and excess sulfate index is linearly regressed for the samples with $\mathrm{SO}_{4}^{2-} / \mathrm{Al}_{\text {insol }}<1.0$, while the logarithmic regression is also applied for Ca DFP vs $\mathrm{SO}_{4}^{2-} / \mathrm{Al}_{\text {insol }}$ ratio for all the samples. $n$ in the figures means the number of the samples.

averages 1047 (ranging from 15 to 10805 ) $\mathrm{ng} \mathrm{g}^{-1}$, while nitrate averages 650 (ranging from 18 to 3453) $\mathrm{ng} \mathrm{g}^{-1}$. The acids will strengthen the dissolution of some acid-dissolvable materials, and increase the concentration of the dissolved fraction and change the DFP in the snow. Acidification (to $\mathrm{pH}=2.0$ ) of UG1 snow samples shows that the dissolved fraction of some elements (e.g. Fe) will increase greatly (Wu and others, 2012). The DFPs of both Ca and Na show a close correlation $(p<0.01$, significant) with the sulfate and nitrate concentration (Fig. 4), indicating that $\mathrm{Ca}$ and $\mathrm{Na}$ are very easily affected by acid input. Whereas the DFPs of $\mathrm{K}$ and $\mathrm{Mg}$ show no regular correlation with sulfate and nitrate, suggesting that $\mathrm{K}$ and $\mathrm{Mg}$ are more independent of the acid input and seem more stable in the post-depositional processes than $\mathrm{Ca}$ and $\mathrm{Na}$.

As pointed out by previous researchers, sulfate is preferentially eluted over calcium (Eichler and others, 2001; Li and others, 2006). The relatively low sulfate fraction might result from the low acid input and/or elution, while the high one indicates the anthropogenic input. In this study, we used the concentration ratio between sulfate and dust $\left(\mathrm{SO}_{4}^{2-} / \mathrm{Al}_{\text {insol, }}\right.$, both with unit of $\left.\mathrm{ng} \mathrm{g}^{-1}\right)$, instead of the absolute sulfate concentration, as the index of anthropogenic acid input to the surface snow, and assumed that there was excess acid input when this ratio was greater than a given threshold (possibly $\mathrm{SO}_{4}^{2-} / \mathrm{Al}_{\text {insol }}=1.0$ ). This tentative threshold is an arbitrary standard to show the input amount of acid relatively compared with dust. An increase in the $\mathrm{SO}_{4}^{2-}$ / $\mathrm{Al}_{\text {insol }}$ ratio means there was more acid input and consequently strengthened acid-dissolution than under normal conditions. Extremely low $\mathrm{SO}_{4}^{2-} / \mathrm{Al}_{\text {insol }}$ ratios $(<0.1)$ mostly occurred during melting periods and showed a co-occurrence with a low DFP, indicating strong elution, since $\mathrm{SO}_{4}^{2-}$ is the most preferentially eluted ion at this site ( $\mathrm{Li}$ and others, 2006). Generally, the DFPs increase with high $\mathrm{SO}_{4}^{2-} / \mathrm{Al}_{\text {insol }}$ ratios, but become rather stable ( $\mathrm{Na}$ and $\mathrm{Mg}$ ) or even decrease (Ca) when this ratio exceeds $\sim 1.0$ (Fig. 4), suggesting that the acid-caused dissolution has a threshold.

\subsection{The DFP of the four major crustal elements and the elution sequence}

Some samples have a high (or relatively high) concentration both in the dissolved and insoluble fractions. Although samples 2006.04.21, 2007.04.11, 2007.05.03, 2007.10.03, and 2009.10.24 have dust $\left(\mathrm{Al}_{\text {insol }}\right)$ concentrations much greater than average, they show normal DFP values (Fig. 7). Here, the 'normal DFP' was defined as the DFP of those samples that experienced no melting. Since those samples were collected during spring or fall with daily air temperatures lower than the melting threshold, they are classified as the unmelted case. In contrast, some low $\mathrm{Al}_{\text {insol }}$ concentration samples show a high DFP, such as those collected on 2006.05.27, 2006.07.12, 2007.06.13, 2007.07.11, 2009.03.28, and 2009.04.04, due to the relatively high concentration of the dissolved fraction, that was probably caused by acid input (see discussion in Section 4.2).

The DFPs show a downward trend when plotted against dust concentration, and most low DFP samples contain a high $\mathrm{Al}_{\text {insol }}$ concentration (Fig. 5), suggesting the high dust 

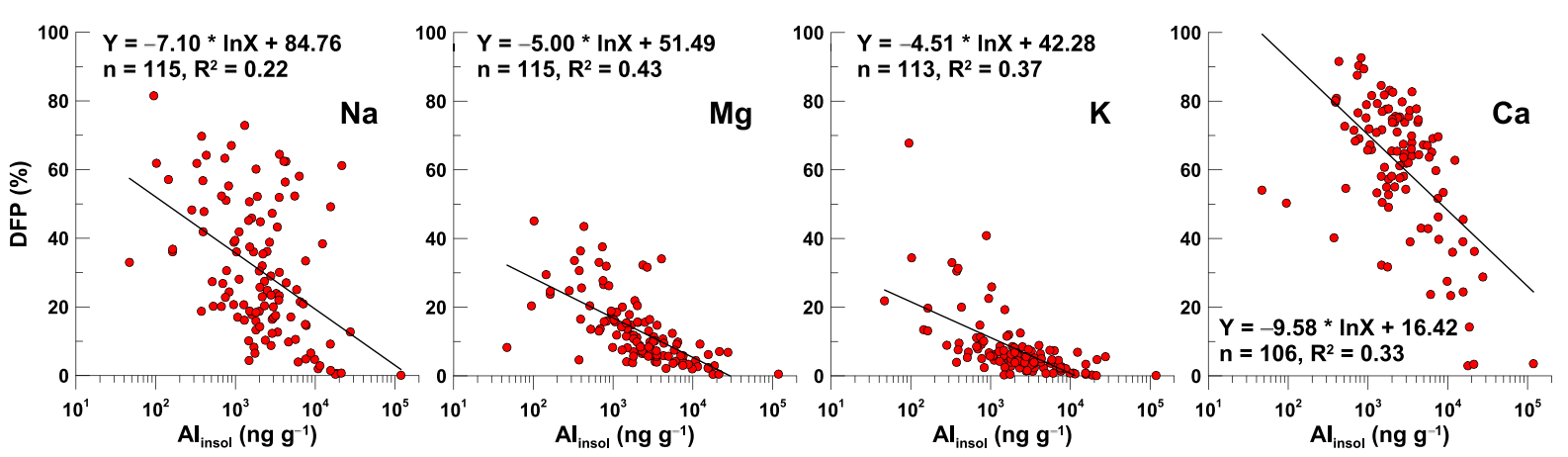

Fig. 5. The DFP vs dust (insoluble Al element) concentration of UG1 snow samples. All the correlations are significant $(p<0.01)$. The logarithmic scale was used to give a clear indication of the low concentration samples.

concentration in the snow resulted either from the heavy dust input or from the accumulation of insoluble microparticles by elution, or both. The contribution of elution-induced accumulation can be identified by the DFP, which is useful in explaining the high dust concentration in snowpack and ice core records.

As shown in Figure 6, there are still variations in the DFP during cold periods (daily air temperature $<1.4^{\circ} \mathrm{C}$ at the Daxigou station) without corresponding changes in acid input (see discussion in Section 4.2). For example, during the cold period between October 2007 and March 2008 (the gray band in Fig. 6) the DFP varied from 9.8 to $39.4 \%$ for $\mathrm{Na}$, while from 2.4 to $19.3 \%$ for $\mathrm{K}$. Those variations indicate that in addition to temperature and acid input, other factors could also affect the DFP, such as atypical additional sources or compaction of the snow, since precipitation (snowfall) is infrequent during the winter.

Over the period 24 January to 28 February 2007, the samples have stable, low DFPs, with low temperatures and minimal acid input. Whereas for the period from 26 July to 10 August 2006, the samples have extremely low DFPs for all the elements, and have the lowest acid input. Therefore, the two periods were chosen to represent typical unmelted and eluted samples, respectively.

Calcium has the most variable and highest average DFP. The lowest Ca DFP occurred during the warm season, clearly indicating strong elution. Furthermore, all the low Ca DFP $(<30 \%)$ samples derived from the warm season, with 24 October 2009 (sample 2009.10.24) being the only exception. For the elements $\mathrm{Na}, \mathrm{K}$, and $\mathrm{Mg}$, almost all the extremely low DFPs occurred during the warm season, with very few exceptions. Therefore, the DFPs in the cold and warm seasons can also generally represent the unmelted and eluted states. According to the meteorological record at the Daxigou station, all of the days with a daily temperature of $\geq 1.4^{\circ} \mathrm{C}$ were grouped into the warm season, and the rest into the cold season (Table 2). During the warm season, the average DFP of those four elements is lower than that in cold season, indicating that elution has happened during summer. Only K shows the discrepancy that its DFP is slightly higher during warm season, possibility due to the low DFPs during the two seasons.

The difference in the DFP $(\triangle \mathrm{DFP})$ between the unmelted and eluted stages for a given species, therefore, can reflect the strength of elution. Furthermore, the preferential elution of the ions will lead to variation in the $\triangle$ DFPs for these elements and might provide an effective method to quantitatively characterize the elution sequence. Calcium has the greatest $\triangle \mathrm{DFP}(50.2 \%)$ among the four elements, followed by $\mathrm{Na}(18.7 \%)$ and $\mathrm{Mg}(6.1 \%)$, and $\mathrm{K}$ has the lowest one $(3.2 \%)$. This result is consistent with that of the cold-warm season. Based on the $\triangle \mathrm{DFP}$ between the typical unmelted and eluted stages and between the warm and cold seasons, the elution sequence for the four elements $\mathrm{Ca}>\mathrm{Na}>$ $\mathrm{Mg}>\mathrm{K}$ was obtained, same to the previous result between March 2006 and December 2007 (Zhang and others,

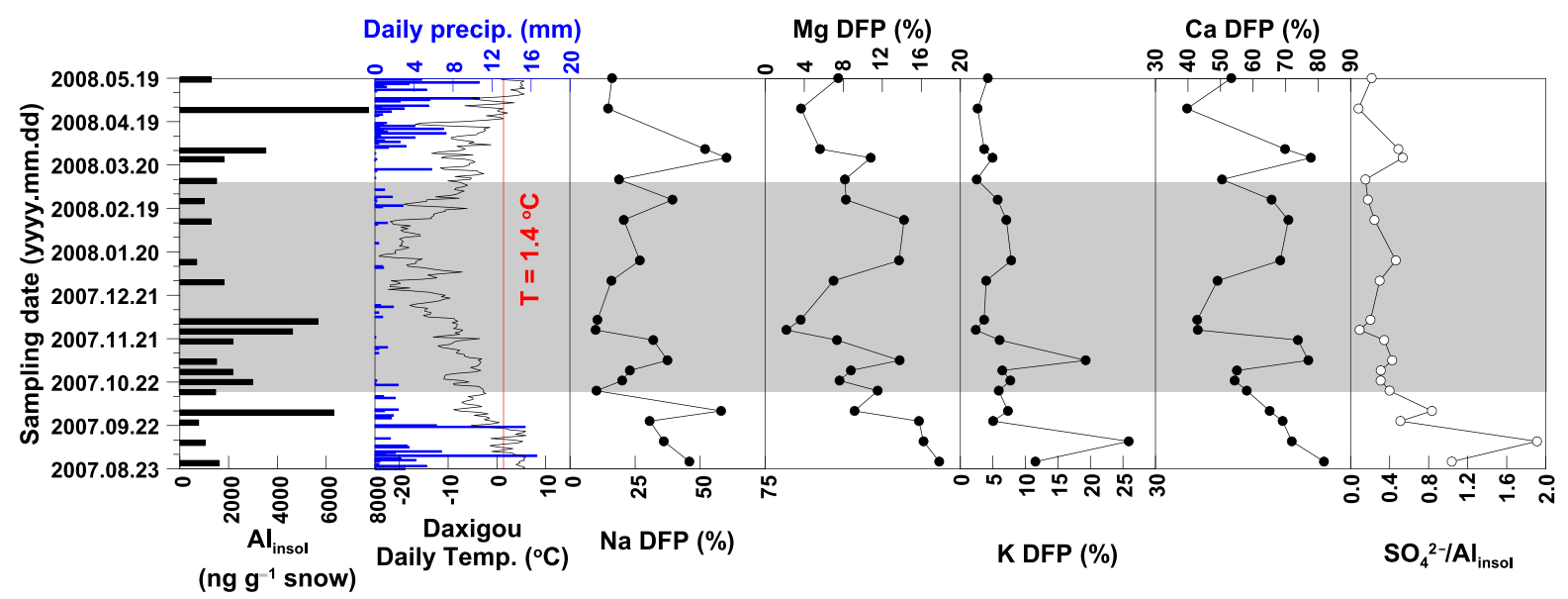

Fig. 6. The DFP profiles for UG1 snow samples during a cold period October 2007 and March 2008 (the gray band). The daily precipitation and temperature data at the Daxigou meteorological station are also shown. The sampling collection date was presented in the format yyyy. mm.dd. 


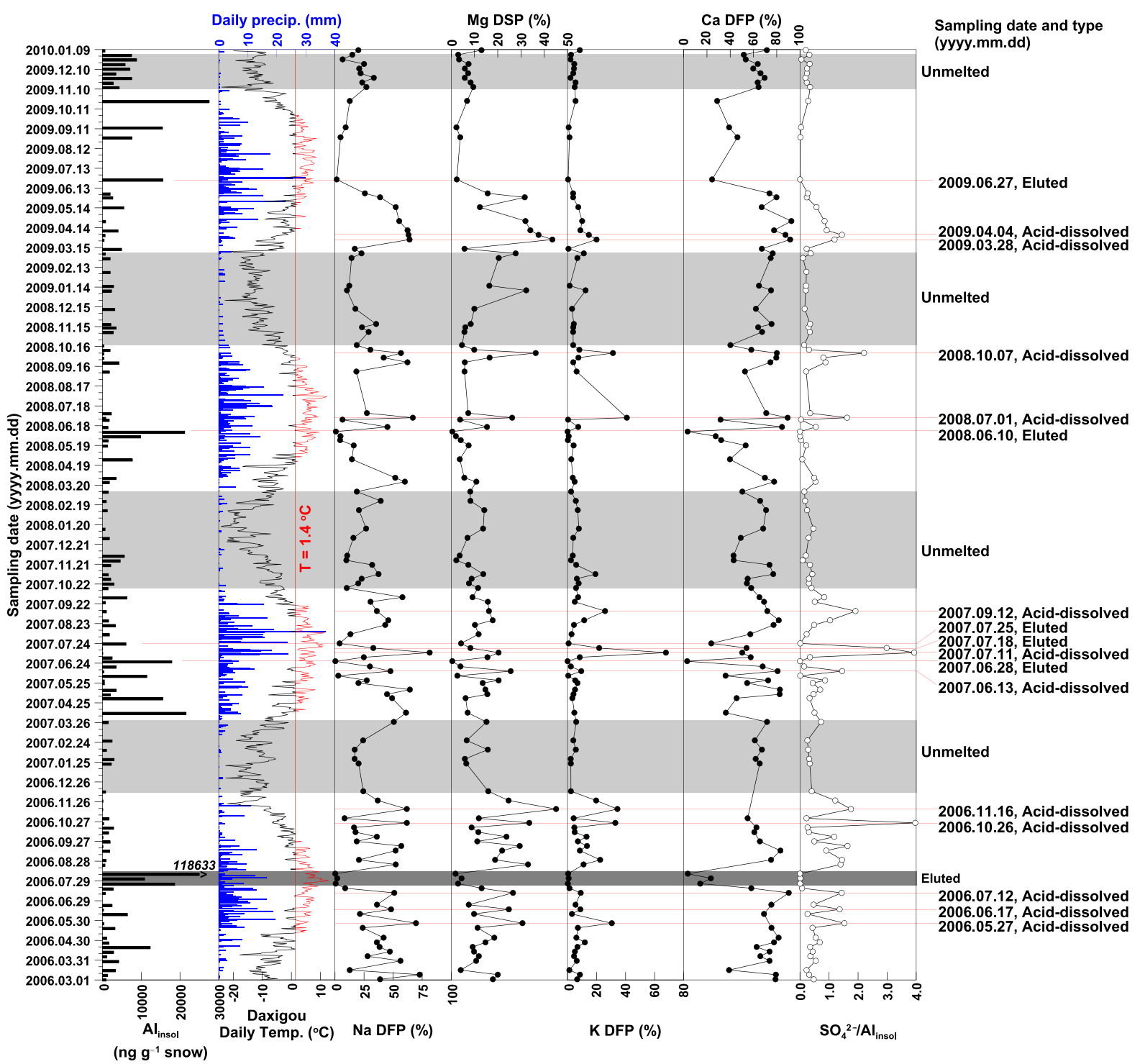

Fig. 7. The DFP profiles for UG1 snow samples during the period March 2006 to January 2010. The daily precipitation and temperature data at the Daxigou meteorological station are also shown. Some samples were chosen to typify the relevant categories. Samples were named according to the collection date in the format yyyy.mm.dd.

2013). This result is very similar to the result of $\mathrm{Ca}^{2+}>$ $\mathrm{Na}^{+}>\mathrm{K}^{+}>\mathrm{Mg}^{2+}$ using the temporal trends in ion concentration ratio relative to the reference value (using $\mathrm{Mg}^{2+}$ as the reference species) (Li and others, 2006). Even in the work of $\mathrm{Li}$ and others (2006) the difference in the elution trend between $\mathrm{K}^{+}$and $\mathrm{Mg}^{2+}$ is very small. Therefore, for the UG1 snow, there is no substantial difference in elution sequences between our results (the DFP results) and previous work (ion ratio results). This validates the method of using the DFP as a possible index to characterize the melting-elution strength. The ion concentration ratio technique is limited to the ions that can be analyzed using the IC technique. While beyond the limitation of the four major cations, our method can be applied to the trace and rare earth elements using the much more precise ICP-MS technique. This geochemical method therefore possibly provides a new technique to determine the elution process more accurately.

Table 2. The average DFP of the four elements between typical unmelted and eluted stages, and between the cold $(n=71)$ and warm $(n=44)$ seasons

\begin{tabular}{|c|c|c|c|c|c|c|}
\hline & Sampling date & Ca DFP & Na DFP & Mg DFP & K DFP & $\mathrm{SO}_{4}^{2-} / \mathrm{Al}_{\text {insol }}$ \\
\hline Eluted & 26 July, 3 and 10 August 2006 & 13.7 & 0.9 & 2.6 & 0.4 & 0.01 \\
\hline Unmelted & 14 and 31 January, 14 and 28 February 2007 & 63.9 & 19.6 & 8.7 & 3.6 & 0.30 \\
\hline$\Delta \mathrm{DFP}$ & & 50.2 & 18.7 & 6.1 & 3.2 & \\
\hline Cold season & & 65.2 & 32.1 & 13.8 & 7.5 & \\
\hline Warm season & & 55.5 & 27.9 & 12.3 & 8.6 & \\
\hline
\end{tabular}


Table 3. The detailed information of some typical cases. The daily temperature at the Daxigou station is in the unit ${ }^{\circ} \mathrm{C}$

\begin{tabular}{|c|c|c|c|c|c|c|c|c|}
\hline Type & Sample & $\mathrm{Na}$ DFP & Mg DFP & K DFP & Ca DFP & $\mathrm{SO}_{4}^{2-} / \mathrm{Al}_{\text {insol }}$ ratio & Daily temp. & Note \\
\hline Unmelted & 2008.01 .15 & 26.8 & 13.7 & 7.8 & 68.4 & 0.46 & -16.7 & \\
\hline Unmelted & 2008.12 .13 & 17.5 & 9.9 & 3.2 & 62.0 & 0.16 & -16.1 & \\
\hline Acidified & 2006.10 .26 & 61.8 & 33.6 & 33.0 & & 3.97 & -4.9 & \\
\hline Acidified & 2008.07 .01 & 67.0 & 26.2 & 40.8 & 89.4 & 1.62 & 5.1 & \\
\hline Acidified & 2009.03.28 & 64.2 & 43.5 & 20.0 & 91.6 & 1.19 & -9.3 & \\
\hline Eluted & 2007.06 .28 & 0.4 & 0.4 & & 2.9 & $<0.01$ & 7.5 & \\
\hline Eluted & 2008.06.10 & 0.7 & 0.5 & 0.1 & 3.4 & $<0.01$ & 9.5 & \\
\hline Eluted & 2009.06 .27 & 1.5 & 2.4 & 0.42 & 24.4 & $<0.01$ & 4.3 & \\
\hline Complex & 2007.07 .11 & 81.5 & 20.4 & 67.7 & 50.3 & 3.93 & 5.8 & $\mathrm{Na}, \mathrm{Mg}, \mathrm{K}$ acidified, and Ca eluted \\
\hline Complex & 2007.07.18 & 32.9 & 8.2 & 21.8 & 54.0 & 2.98 & 2.8 & $\mathrm{~K}$ acidified, $\mathrm{Na}, \mathrm{Mg}$, and Ca eluted \\
\hline
\end{tabular}

Note: Some typical unmelted and eluted cases are also listed in Table 2.

The ion elution of melting snow has been studied at many sites, but with different sequence results. The elution sequence is $\mathrm{SO}_{4}^{2-}>\mathrm{Ca}^{2+} \sim \mathrm{Mg}^{2+}>\mathrm{K}^{+} \sim \mathrm{Na}^{+}>\mathrm{NO}_{3}^{-}>\mathrm{Cl}^{-}$in the Grenzgletscher ice core, southern Alps (Eichler and others, 2001), $\mathrm{K}^{+}>\mathrm{SO}_{4}^{2-}>\mathrm{NO}_{3}^{-}>\mathrm{Cl}^{-}>\mathrm{Ca}^{2+}>\mathrm{Mg}^{2+}>\mathrm{Na}^{+}$at Baishui Glacier No. 1, southwest China (Zhang and others, 2010), and $\mathrm{SO}_{4}^{2-}>\mathrm{K}^{+}>\mathrm{Ca}^{2+}>\mathrm{Mg}^{2+}>\mathrm{Na}^{+}>\mathrm{Cl}^{-}>\mathrm{NO}_{3}^{-}$ at Shiyi Glacier, Qilian Mountains (Li and others, 2015). Svalbard ice cores indicate that non-sea-salt Mg is particularly sensitive to melting (Kekonen and others, 2005). Using the synthetic ice core approach, a partial elution sequence for the summit of Lomonosovfonna, as $\mathrm{NO}_{3}^{-}>\mathrm{SO}_{4}^{2-}, \mathrm{Mg}^{2+}, \mathrm{Cl}^{-}$, $\mathrm{K}^{+}, \mathrm{Na}^{+}$, was obtained (Vega and others, 2016). However, at UG1, $\mathrm{Na}$ is preferentially eluted over $\mathrm{Mg}$ (this study and $\mathrm{Li}$ and others, 2006). The regional constraint on elution sequences might be caused by other factors (e.g. sea salt and crust sources; dust composition) that are beyond the scope of this paper. Nevertheless, our method can be applied at different sites, including those in the low latitudes to constrain the elution sequences.

Since Ca is susceptible to post-depositional processes and is most preferentially eluted by meltwater, it is reasonable to be cautious when using calcium as the dust index in snow and ice cores from low-latitudes and low-altitudes. Based on the elution sequence, $\mathrm{Mg}$ seems to be a better species for the dust index than Ca.

\subsection{DFP as a potential quantitative index for melting events in UG1: case studies}

Using DFP as the potential index for the strength of elution requires two conditions simultaneously: the element has a crustal origin and the variation of the DFP was caused by elution. Both conditions are met based on the discussion in Sections 4.1 and 4.3. Therefore, the DFP will change corresponding to the strength of elution, making it possible to use this ratio to reflect the elution process. The ion concentration can only indicate the relative elution sequence to a reference ion. While, since the DFP of those elements is independent of each other, the combination and comparison of those DFPs can provide new and more detailed information on the elution process. With the acid input index, the different elution states, e.g. unmelted, acid-dissolved, and eluted, can be classified.

Typical unmelted snow samples can be found during the winter season (gray bands in Fig. 7), such as the stage from 24 January to 28 February 2007 (Table 2), with stable and moderate DFPs and weak fluctuations.
The acid-dissolved cases occur with high $\mathrm{SO}_{4}^{2-} / \mathrm{Al}_{\text {insol }}$ ratios (>1.0). Sample 2006.10.26 has the highest $\mathrm{SO}_{4}^{2-}$ / $\mathrm{Al}_{\text {insol }}$ ratio $(=3.97)$, suggesting that the acid input accounts for its high DFP since it was collected during the latter part of fall (low temperatures) when melting was absent (Table 3). Even during the summer and with high temperatures, there are also some acid-dissolved cases (e.g. 2008.07.01), possibly due to sampling being carried out just after dissolution but before elution.

Eluted cases occur mostly during the warmest period from June to August. Between 26 July and 10 August 2006, the air temperature rose to the warmest of the year, which enabled and resulted in strong elution (the dark gray band in Fig. 7). A high dust (insoluble fraction) concentration in snow and ice cores can result from heavy dust input and/or compaction caused by melting and elution. The high dust concentration samples collected on 26 July, 3 and 10 August 2006 might be partly due to the melting-elution during the period with the highest daily temperature of the year, which lasted from 19 July to 9 August 2006 (Wu and others, 2010). Correspondingly, the DFP value is extremely low $(0.1 \%$ for $\mathrm{Na}, 0.5 \%$ for $\mathrm{Mg}, 0.1 \%$ for $\mathrm{K}$, and $3.5 \%$ for $\mathrm{Ca}$ ) for the sample with the highest dust concentration (2006.08.10, $\mathrm{Al}_{\text {insol }}=118633 \mathrm{ng} \mathrm{g}^{-1}$ ), confirming that the high dust concentration of this sample is clearly affected by elutioninduced accumulation, although heavy dust input was the predominant contribution. Similar cases were found in samples 2007.06.28, 2008.06.10, and 2009.06.27 (Fig. 7). The DFP therefore serves as an effective index to identify whether high dust concentration was caused by strengthened input, or partly resulted from post-depositional accumulation from melting and elution.

For some samples, the four species could be classified into different cases due to their elution strength. Sample 2007.07.11 has the second highest $\mathrm{SO}_{4}^{2-} / \mathrm{Al}_{\text {insol }}$ ratio $(=3.93)$ and a high DFP for $\mathrm{Na}(81.5 \%)$ and $\mathrm{Mg}(20.4 \%)$, in particular the highest K DFP $(67.7 \%)$ for the whole sampling period, indicating that the DFP of this sample is affected by acid input. However, the relatively low (50.3\%) Ca DFP suggests this sample might have undergone weak elution, as $\mathrm{Ca}$ is the most preferentially eluted cation. Therefore, sample 2007.07.11 can be classified as an acid input case from the elevated DFP for $\mathrm{Na}, \mathrm{Mg}$, and $\mathrm{K}$, but also as the weakly eluted case from the Ca DFP. Although sample 2007.07.18 has the third highest $\mathrm{SO}_{4}^{2-} / \mathrm{Al}_{\text {insol }}$ ratio $(=2.98)$, the low DFPs for Ca (54\%), $\mathrm{Na}(32.9 \%)$, and $\mathrm{Mg}(8.3 \%)$ clearly indicate an eluted case, while the high-K DFP (21.8\%) suggests that $\mathrm{K}$ is still at an acid-dissolved state due to $\mathrm{K}$ being the least preferentially eluted species among them. Therefore, 
sample 2007.07.11 indicates a state of acid-dissolution and the initial stages of elution, while sample 2007.07.18 represents the ending of elution (Table 3). The variation of DFPs for a given sample is useful to identify additional detail in the acidification or elution process, and reveals that ion elution is a process more complex than revealed simply by the temporal trends of ion concentration ratios.

\subsection{Uncertainties and future work}

Compared with the elution sequence from ion concentration, the DFP is an improved method. The geochemical index (DFP) of those elements is independent of each other $(\mathrm{Na}$, $\mathrm{Mg}, \mathrm{K}$, and $\mathrm{Ca}$ ) and can provide new and more detailed information on the elution process. Ion concentration alone seems insufficient to detail the classification of elution. In addition, DFP can be applied to the trace and rare earth elements besides $\mathrm{Na}, \mathrm{Mg}, \mathrm{K}$, and $\mathrm{Ca}$. As we pointed out in the Introduction, the ion concentration method might produce uncertainty since the reference ion itself is also affected by elution. Finally, the ICP-MS technique is much more accurate than IC for the major elements in the dissolved fraction.

Although this geochemical-based DFP index provides an effective approach for assessing the elution strength of surface snow, some considerable uncertainties in the results and their implications remain and need examination. It is assumed that the dust has a stable composition. In winter, the DFP, especially for $\mathrm{Ca}$, did not always show the same or even a stable level (Fig. 7), suggesting that the assumption of compositional homogeneity is somewhat simplified and idealized. If an additional dissolved fraction (e.g. salt) was attached to the surface of the dust particles, the original DFP will change accordingly.

The absolute DFP value might have a regional to local implication due to the mineral composition of these dust samples. For example, the UG1 snow samples show that $\mathrm{Ca}$ has the highest DFP, while the Sahara dust in the loess from Cape Verde Island shows the highest Na solubility, higher than $\mathrm{Ca}, \mathrm{K}$, and Mg (Desboeufs and others, 2001). However, using the variation of the DFP ( $\triangle \mathrm{DFP})$ to evaluate the elution strength is applicable at different sites, regardless of the absolute DFP value of a given crustal (or natural) species.

Some high DFPs might be caused by the input of excess acids. This effect can superimpose on melting and elution during the warm season. The $\mathrm{SO}_{4}^{2-} / \mathrm{Al}_{\text {insol }}$ ratio was used as the index of excess acid input from anthropogenic sources. However, this ratio is also affected by the post-depositional elution process, as sulfate can be eluted during the warm season (Eichler and others, 2001; Li and others, 2006).

There are still two uncertainties in the field sampling itself. The first is the spatial uncertainty, which has been reported to be considerable for ice core and snow samples over a short distance (Steig, 2008), although it is generally $<10 \%$ of mean ion concentration in the UG1 basin (Williams and others, 1992). The second is the temporal uncertainty of relatively long sampling intervals, since the melting and elution processes can occur in a time span far shorter than a week (a few samples have even longer collection intervals) time span. Although the sampling period lasted nearly 4 years, the collection was not consecutively carried out due to limited logistics, such as the two neighboring samples collected on 8 July and 9 September 2008. Therefore, some samples might have experienced a melting-elution-re-freezing cycle and multi-precipitation (snowfall) events, which complicates characterizing elution using geochemical data that represent the final state before sampling. For some summer samples, they may simply reflect the state of the sampling time of the surface snow deposited by the last snowfall. Parallel, consecutive and high-frequency sampling is required for more representative data in future work.

In ice core records, especially those used for geochemical analysis, a single sample might represent a seasonal to multiyear time interval and might cover more than one precipitation-melting-elution-re-refreezing cycle, depending on the temporal resolution. Therefore, using the DFP index to characterize elution seems to be limited to samples with seasonal or higher resolution.

\section{CONCLUSIONS}

In this study, we applied a new geochemical method to characterize the elution of surface snow on UG1, based on detailed measurement of the concentration of dissolved and insoluble fractions of four major crustal elements: $\mathrm{Na}$, $\mathrm{Mg}, \mathrm{K}$, and $\mathrm{Ca}$. Using the DFP index, our results detail the variation of concentration for the dissolved and insoluble fractions of the four elements and their elution in the UG1 surface snow. The dust in the UG1 snow has a crustal origin and compositional homogeneity. Calcium has the greatest DFP among those elements, followed by $\mathrm{Na}, \mathrm{Mg}$, and $\mathrm{K}$ in descending order. The variations in DFP between the typical unmelted and eluted stages and between the warm and cold seasons are used to characterize the elution strength, showing the elution sequence $\mathrm{Ca}>\mathrm{Na}>\mathrm{Mg}>\mathrm{K}$ for the four elements. This sequence is consistent with that shown by the ion concentration method, and verifies our method. Calcium is most preferentially eluted by postdepositional processes, suggesting that using $\mathrm{Ca}^{2+}$ as the climatic and environmental (such as dust) index in the low-latitude and/or low-altitude ice cores should be carefully considered.

The input of acids could also increase the DFP, and this effect can be estimated from the index of the concentration ratio between acid and dust $\left(\mathrm{SO}_{4}^{2-} / \mathrm{Al}_{\text {insol }}\right)$. The DFP index can also be used to detect whether the high dust (insoluble fraction) concentrations in summer are induced by atmospheric dust input or are from the post-depositional elution-induced accumulation. In addition, the DFP for different elements also reflects their different elution states, e.g. unmelted, eluted, and acid-dissolved, which the ion concentration is insufficient to discern. The state of aciddissolution and the initial stages of elution (sample 2007.07.11) and the state of the ending of elution (sample 2007.07.18) can also be found by DFP and acid input index. This method has not yet provided a definitive reconstruction of the melting and elution history of snow because such processes are complex, and many uncertainties remain. The DFP index provides an effective and possibly quantitative or semi-quantitative assessment of the snow melt/elution process and will be helpful to understand the ice core records in low-latitude and/or low-altitude. Our geochemical index appears to be better than using the ion concentration comparison alone, since the DFP of those elements is independent of each other, the combination and comparison of those DFPs can provide new and more detailed information on the elution process. In addition, our method can be applied to the elution of trace and rare earth elements. 


\section{ACKNOWLEDGEMENTS}

We are grateful to the Tien Shan Glaciological Station for the fieldwork at Urumqi Glacier No. 1 and Caroline Brimblecombe for improving the text. We also thank two anonymous reviewers and Editor Michelle Koutnik and Hester Jiskoot for their comments. This work is supported by the National Natural Science Foundation of China (Grant No. 41725001) and the Strategic Priority Research Program of Chinese Academy of Sciences (Grant No. XDA20060201).

\section{REFERENCES}

Alley RB and Anandakrishnan S (1995) Variations in melt-layer frequency in the GISP2 ice core: implications for Holocene summer temperatures in central Greenland. Ann. Glaciol. 21, 64-70 (doi: 10.1017/S0260305500015615).

Balerna A and 5 others (2003) Chemical and radio-chemical composition of fresh snow samples from northern slope of Himalayas (Cho Oyu range, Tibet). Atmos. Environ., 37(12), 1573-1581 (doi: 10.1016/S1352-2310(03)00009-8).

Desboeufs K, Losno R and Colin J (2001) Factors influencing aerosol solubility during cloud processes. Atmos. Environ., 35(20), 3529-3537 (doi: 10.1016/S1352-2310(00)00472-6).

Eichler A, Schwikowski M and Gaggeler H (2001) Meltwaterinduced relocation of chemical species in alpine firn. Tellus $B$ 53(2), 192-203 (doi: 10.1034/j.1600-0889.2001.d01-15.x).

Fisher D and 6 others (2012) Recent melt rates of Canadian Arctic ice caps are the highest in four millennia. Global Planet. Change, 84-85, 3-7 (doi: 10.1016/j.gloplacha.2011.06.005).

Harrington R and Bales RC (1998) Modeling ionic solute transport in melting snow. Water Resour. Res., 34(7), 1727-1736 (doi: 10.1029/98WR00557).

Hou SG, Qin DH and Huang CL (1996) The elution of ions in two snow pits in the Dongkemadi Glacier, Tanggula Range. J. Glaciol. Geocryol., 18(3), 227-234 [in Chinese].

Huang CL, Li ZQ, Hou SG and Pu JC (1997). Effects of ion elution on formation of ice core record. Chin. Sci. Bull., 42(3), 236-238 (doi: 10.1007/BF02882444).

Johannessen M and Henriksen A (1978) Chemistry of snow meltwater changes in concentration during melting. Water Resour. Res., 14(4), 615-619 (doi: 10.1029/WR014i004p00615).

Kameda T and 5 others (1995) Melt features in ice cores from site J, southern Greenland: some implications for summer climate since AD 1550. J. Glaciol., 21, 51-58 (doi: 10.3198/1995AoG211-51-58).

Kekonen T and 6 others (2005) The 800 year long ion record from the Lomonosovfonna (Svalbard) ice core. J. Geophys. Res., 110, D07304 (doi: 10.1029/2004JD005223).

Koerner RM (1997) Some comments on climatic reconstructions from ice cores drilled in areas of high melt. J. Glaciol., 43(143), 90-97 (doi: 10.3198/1997JoG43-143-90-97).

Kohno S and Maeno N (1979) Migration of solid particles in melting snow. Low Temp. Sci., A38, 81-92.

Li ZQ and 8 others (2006) Seasonal variability of ionic concentrations in surface snow and elution processes in snow-firn packs at the PGPI site on Glacier No. 1 in eastern Tien Shan, China. Ann. Glaciol., 43, 250-256 (doi: 10.3189/172756406781812069).

Li XY, Li ZQ and Ding YJ (2007a) Seasonal variations of $\mathrm{pH}$ and electrical conductivity in a snow-firn pack on Glacier No. 1, eastern Tianshan, China. Cold Reg. Sci. Technol., 48, 55-63 (doi: 10.1016/j.coldregions.2006.09.006).
Li ZQ, Li CJ, Li YF and Wang FT (2007b) Preliminary results from measurements of selected trace metals in the snow-firn pack on Urumqi glacier No. 1, eastern Tien Shan, China. J. Glaciol., 53 (182), 368-373 (doi: 10.3189/002214307783258486).

Li ZX and 10 others (2015) The evolution and environmental significance of glaciochemistry during the ablation period in the north of Tibetan Plateau, China. Quat. Int., 374, 93-109 (doi: 10.1016/ j.quaint.2014.06.071).

Steig EJ (2008) Sources of uncertainty in ice core data. A contribution to the Workshop on Reducing and Representing Uncertainties in High-Resolution Proxy Data. http://www.ncdc.noaa.gov/paleo/ reports/trieste2008/ice-cores.pdf.

Takeuchi N and Li ZQ (2008) Characteristics of surface dust on Ürümqi Glacier No. 1 in the Tien Shan Mountains, China. Arct. Antarct. Alp. Res., 40(4), 744-750 (doi: 10.1657/1523-0430(07094)).

Tsiouris S, Vincent CE, Davies TD and Brimblecombe P (1985) The elution of ions through field and laboratory snowpacks. Ann. Glaciol., 7, 196-201 (doi: 10.1017/S0260305500006169).

Vega CP and 9 others (2016) A synthetic ice core approach to estimate ion relocation in an ice field site experiencing periodical melt: a case study on Lomonosovfonna, Svalbard. Cryosphere, 10, 961-976 (doi: 10.5194/tc-10-961-2016).

Wake CP and 5 others (1992) Anthropogenic sulfate and Asian dust signals in snow from Tien Shan, northwest China. Ann. Glaciol., 16, 45-52 (doi: 10.3198/1992AoG16-1-45-52).

Watanabe K, Hirai T and Kawada K (2015) Ratios of $\mathrm{Mg}^{2+} / \mathrm{Na}^{+}$in the snow cover at Murododaira, Mt. Tateyama, Japan: on the possibility of an indicator of chemical leaching. Bull. Glaciol. Res., 33, 1-5 (doi: 10.5331/bgr.33.1).

Williams MW, Tonnessen KA, Melack JM and Yang DQ (1992) Sources and spatial variation of the chemical composition of snow in the Tien Shan, China. Ann. Glaciol., 16, 25-32 (doi: 10.3198/1992AoG16-1-25-32).

Wong GJ, Hawley RL, Lutz ER and Osterberg EC (2013) Traceelement and physical response to melt percolation in Summit (Greenland) snow. Ann. Glaciol., 54(63), 52-62 (doi: 10.3189/ 2013AoG63A602)

Wu JF, Boyle E, Sunda W and Wen L-S (2001) Soluble and colloidal iron in the oligotrophic North Atlantic and North pacific. Science, 293, 847-849 (doi: 10.1126/science. 1059251).

Wu GJ, Xu BQ, Zhang CL, Gao SP and Yao TD (2009) Geochemistry of dust aerosol over the Eastern Pamirs. Geochim. Cosmochim. Acta, 73(4), 977-989. (doi: 10.1016/j.gca.2008.11.022).

Wu GJ and 6 others (2010) Concentration and composition of dust particles in surface snow at Urumqi Glacier No. 1, Eastern Tien Shan. Global Planet. Change, 74, 34-42 (doi: 10.1016/j. gloplacha.2010.07.008).

Wu G), Zhang CL, Li ZQ, Zhang XL and Gao SP (2012) Iron content and solubility in dust from high-alpine snow along a north-south transect of high Asia. Tellus B, 64, 17735 (doi. org/10.3402/ tellusb.v64i0.17735)

Ye B and 6 others (2005) The Urumqi river source Glacier No. 1, Tianshan, China: changes over the past 45 years. Geophys. Res. Lett., 32, L21504, doi: 10.1029/2005GL024178.

Zhang NN and 5 others (2010) Preliminary study of transformation of snow to ice and ion elution during ablation period at a typical temperate glacier region. J. Glaciol. Geocryol., 32(3), 505-513 [in Chinese].

Zhang CL and 7 others (2013) Distribution of major elements between the dissolved and insoluble fractions in surface snow at Urumqi Glacier No. 1, Eastern Tien Shan. Atmos. Res., 132133, 299-308 (doi. org/10.1016/j.atmosres.2013.05.009). 